\title{
BIOLOGIA MOLECULAR
}

\author{
NOTA \\ CARACTERIZAÇÃO DE GERMOPLASMA DE SOJA E DE \\ FEIJÀO ATRAVÉS DE ELETROFORESE DE ISOENZIMAS \\ DA SEMENTE ${ }^{(1)}$
}

ANA BEATRIZ ANTI ${ }^{(2)}$

\section{RESUMO}

Foram estudadas, através de eletroforese em gel de poliacrilamida, isoenzimas de sementes de plantas de dois cultivares de soja, IAC 6 e IAC 9, e de duas linhagens de feijão da variedade Goiano Precoce, uma com folha lisa e outra com folha rugosa, tendo em vista sua caracterização. Apesar de possuírem um parental em comum, os dois cultivares de soja diferiram entre si com relação aos perfis eletroforéticos de urease, fosfatase ácida, malato desidrogenase e leucina aminopeptidase evidenciando que essa técnica pode ser usada para discriminar outros cultivares de soja; entretanto as duas linhagens de feijão não diferiram entre si nos zimogramas estudados, indicando um grande parentesco e reforçando a hipótese de que a linhagem de folha rugosa poderia ter-se originado da linhagem de folha lisa por mutação de ponto.

Palavras-chave: soja, feijão, eletroforese, isoenzimas, cultivares, caracterização.

\section{ABSTRACT \\ SOYBEAN AND BEAN GERMOPLASM CHARACTERIZATION BY ELECTROPHORESIS OF SEED ISOENZYMES}

Seed isoenzymes of two soybean cultivars, IAC 6 and IAC 9, and two lines of the bean cultivar Goiano Precoce, one with smooth leaves and the other with wrinkled leaves, were studied through electrophoresis. The plants of soybean cultivars differed for the isoenzymes urease, acid phosphatase, malic dehydrogenase and leucine aminopeptidase. The results indicate that the two cultivars of soybean are very different genetically, despite their origin from a single, older variety. The eletrophoretic characters which differed between the two soybean cultivars may have potentiality for discriminating them among other cultivars. On the other hand, the lines of these bean cultivars did not differ in any of the analysed characters that would indicate a very close relationship between them. These results are consistent with the hypothesis, from morphological data, that wrinkled leaves Goiano Precoce could be originated from the other line with smooth leaves through a point mutation.

Key words: soybean, bean, electrophoresis, isoenzymes, cultivars, characterization.

\section{Introdução}

No campo as características morfológicas são utilizadas normalmente para descrever e discriminar variedades e novas linhagens de plantas. Entretanto, diferenças genéticas são expressas inicialmente na forma de ácidos nucléicos e proteínas, podendo ser usadas para caracterizar cultivares através de eletroforese. $\mathrm{O}$ uso de isoenzimas substituindo expressões

$\left.{ }^{1}\right)$ Parte da dissertação de Mestrado “Caracterização de Linhagens de Soja e Feijão através de Eletroforese”, da autora, apresentada ao Centro de Energia Nuclear na Agricultura, da Universidade de São Paulo (USP). Recebido para publicação em 30 de março de 1999 e aceito em 5 de maio de 2000.

$\left(^{2}\right)$ Aluna do curso de pós-graduação em Ciências do Centro de Energia Nuclear na Agricultura, Caixa Postal 96, 13400-970 Piracicaba (SP). 
fenotípicas das plantas na caracterização de cultivares está amplamente difundido, uma vez que propicia a obtenção de padrões altamente repetitivos, visto que as isoenzimas são expressões originárias em sua quase totalidade da constituição genética da planta e, portanto, pouco afetadas por condições ambientais (TANKSLEY e ORTON, 1983).

Os estudos genéticos de soja (Glycine max L. Merrill, $2 \mathrm{n}$-40) podem ser facilitados pela avaliação do grande número de loci que podem ser usados como marcadores. Estes incluem locus condicionando variantes para isoenzimas e que apresentam características ideais para serem usados como marcadores (PALMER e Kilen, 1987).

O objetivo deste trabalho é caracterizar plantas de dois cultivares de soja e de duas linhagens de feijão do cultivar Goiano Precoce, fazendo-se estudos eletroforéticos de isoenzimas extraídas de suas sementes.

\section{Material e Métodos}

Sementes de soja (Glycine max L. Merrill) e de feijão (Phaseolus vulgaris L.) foram cedidas pela Seção de Leguminosas do Instituto Agronômico de Campinas ( IAC).

Os cultivares de soja utilizados foram IAC 6 e IAC 9 (desenvolvidos em 1979 e 1980, respectivamente), tendo sido originados da linhagem $\mathrm{F}_{6}$ obtida pela seleção do bulk RB72-1.

Foram utilizados dois lotes de sementes de feijão do cultivar Goiano Precoce provenientes de plantas que diferiam em apenas uma característica: um lote era proveniente de plantas com folhas lisas (normal) e o outro de plantas com folhas rugosas e mais espessas (mutante).

As sementes de soja foram trituradas inteiras, ao passo que as de feijão foram trituradas sem casca para evitar a contaminação por compostos fenólicos e peneiradas em peneiras de malha 0,25. Da farinha obtida foram extraídas proteínas em água e em tampão acetato 0,1 mol. $\mathrm{L}^{-1}$ a $\mathrm{pH}$ : 5,5, utilizando-se o método de LeE (1978).

A eletroforese das isoenzimas foi feita em gel de poliacrilamida a 7\%, através do sistema alcalino nãodissociante descrito por DAVIS (1964).

As isoenzimas fosfatase ácida (AP), malato desidrogenase $(\mathrm{MDH})$, peroxidase (PER), esterase (EST), leucina aminopeptidase (LAP), AIA oxidase, urease (UR) e fosfatase alcalina foram detectadas no gel segundo o método descrito em Alfenas et al. (1991), efetuando-se três repetições para cada isoenzima.

\section{Resultados e Discussão}

As isoenzimas urease, peroxidase e MDH apresentaram apenas um locus nos dois cultivares de soja; por sua vez, para as enzimas urease e $\mathrm{MDH}$, os cultivares IAC 6 e IAC 9 diferiram entre si. No cultivar IAC 6 o locus de urease apresentou $\mathrm{Rm}=0,12$; no cultivar IAC 9 o valor de $\mathrm{Rm}$ foi 0,20; para a isoenzima $\mathrm{MDH}$ o valor de Rm obtido com o cultivar IAC 6 foi 0,45; e no cultivar IAC 9 foi 0,49. Particularmente com a isoenzima peroxidase não houve diferenças entre os dois cultivares de soja, tendo ambos apresentado um locus de $\mathrm{Rm}=0,46$.

Os perfis de fosfatase ácida, LAP e esterase apresentaram mais de um locus em cada cultivar de soja, sendo encontradas diferenças entre eles em relação às enzimas fosfatase ácida e LAP. O cultivar IAC 6 apresentou quatro loci de fosfatase ácida cujos Rm foram: 0,$31 ; 0,33 ; 0,47$ e 0,61 , enquanto no cultivar IAC 9 foram encontrados três loci com os valores de Rm: 0,$30 ; 0,49$ e 0,63 . A isoenzima LAP apresentou três loci nos dois cultivares de soja, e estes diferiram significativamente para um dos loci: no cultivar IAC 6 os valores de Rm encontrados foram 0,18; 0,51 e 0,73, e no cultivar IAC 9 os valores de Rm foram 0,19; 0,61 e 0,74 .

Basicamente não foram encontradas diferenças entre os dois cultivares de soja para a enzima esterase; ambos os cultivares apresentaram cinco loci. Os valores de Rm obtidos no cultivar IAC 6 foram 0,$06 ; 0,16$; 0,$29 ; 0,38$ e 0,61 , e no cultivar IAC 9 foram 0,$07 ; 0,15$; 0,$28 ; 0,38$ e 0,62 .

As plantas das linhagens de feijão não diferiram, entre si, quanto aos perfis eletroforéticos de esterase, peroxidase e fosfatase ácida. No quadro 1 nota-se que a isoenzima esterase apresentou três loci, e a variante mais rápida $(\mathrm{Rm}=0,38)$ também se coloriu mais intensamente que as demais. A isoenzima peroxidase apresentou apenas um loci com $\mathrm{Rm}=0,37$. A isoenzima fosfatase ácida apresentou nove loci, dos quais os de $\mathrm{Rm}=0,39$ e de $\mathrm{Rm}=0,71$ coloriram-se mais intensamente.

Diferenças entre as plantas da linhagem de folha lisa e da linhagem de folha rugosa foram observadas nos perfis eletroforéticos das isoenzimas MDH e LAP. $\mathrm{O}$ perfil de MDH na linhagem de folha rugosa apresentou loci com valores de $\mathrm{Rm}$ ligeiramente superiores aos da linhagem de folha lisa, isto é, na linhagem de folha rugosa as variantes de $\mathrm{MDH}$ mostraram-se um pouco mais rápidas que as da linhagem de folha lisa, como pode ser observado no quadro 1. Os perfis eletroforéticos de LAP das duas linhagens de feijão apresentaram três loci, tendo-se a variante mais rápida colorido mais intensamente e 
apresentado o mesmo valor de Rm para as duas linhagens. A linhagem de folha lisa apresentou um locus lento com $\mathrm{Rm}=0,20$ e um locus intermediário com $\mathrm{Rm}=0,52$; a linhagem de folha rugosa, por sua vez, apresentou um locus lento com $\mathrm{Rm}=0,23$ e um locus intermediário com $\mathrm{Rm}=0,55$.

Nos géis das sementes de soja não foi detectada atividade de AIA-oxidase e fosfatase alcalina, e nos géis das sementes de feijão, atividade de AIA-oxidase, urease e fosfatase alcalina, nessas condições.

Os cultivares de soja IAC 6 e IAC 9 foram selecionados da população RB 72-1 (através do método das populações), a qual foi obtida, segundo KIIHL et al. (1979), da geração $\mathrm{F}_{6}$ do cruzamento de (Hill x PI 240-664) com os parentais Viçoja, Hill, Pickett, F 651376 e Davis.

Teoricamente muitas das plantas obtidas por esse método seriam, na geração $\mathrm{F}_{6}$, homozigotas para a maioria dos caracteres observáveis, e, a partir dessa geração, linhagens poderiam ser extraídas de tais populações e suas progênies consideradas linhas puras. Entretanto, como nesse método é necessário selecionar um grande número de plantas nas gerações avançadas para teste de progênie, uma vez que a seleção natural não atua na eliminação de tipos inferiores para características como maturação, resistência a moléstias, acamamento e deiscência das vagens, os cultivares IAC 6 e IAC 9, embora provenientes da mesma população, possuem genótipos diferentes, como se pode observar nos perfis eletroforéticos de algumas isoenzimas estudadas. VELLO et al. (1988) afirmam que o cultivar IAC 6 tem $28 \%$ de genes em comum com o cultivar IAC 9 e classificam tal coeficiente de parentesco como médio, atribuindo-o ao fato de ambos os cultivares apresentarem em comum o parental (Hill x PI 240-664).
No presente trabalho foram estudadas isoenzimas extraídas apenas das sementes e detectadas diferenças tanto na mobilidade como no número de loci. Contudo, WeEden e GotTlieb (1981) afirmam que as diferenças genéticas entre cultivares de soja podem ser melhor avaliadas quando se faz o estudo em frações subcelulares e em diferentes estágios de desenvolvimento das plantas, pois a atividade das isoenzimas varia nas diferentes frações subcelulares, durante o desenvolvimento da planta.

Através dos perfis eletroforéticos das isoenzimas extraídas das sementes de feijão pode-se afirmar que as linhagens não diferem entre si, embora tenha-se observado pequena diferença entre elas nos perfis de LAP, MDH e fosfatase ácida.

Cury (1980), comparando algumas variedades de Phaseolus vulgaris L. através de eletroforese de isoenzimas, não encontrou diferenças entre elas, exceto para a variedade Goiano Precoce que diferiu das demais, principalmente para os perfis de LAP. Além das sementes, o autor estudou diferentes tecidos vegetativos em distintos estágios de desenvolvimento. Como as linhagens estudadas são muito semelhantes, diferindo apenas nas folhas (lisa e rugosa), poder-seiam detectar algumas diferenças isoenzimáticas se fossem utilizados outros órgãos vegetativos além das sementes, tais como folhas para extrair proteínas, conforme sugerido por WEEDEN e GotTLIEB (1980).

Como essas linhagens diferem entre si em apenas uma característica, acredita-se que tal diferença seja oriunda de uma mutação de ponto, isto é, a linhagem de folha rugosa poderia ter-se originado da linhagem de folha lisa, envolvendo, portanto, apenas um gene na mutação, o qual poderia ser identificado através da detecção da isoenzima por ele codificada e, posteriormente, mapeado, investigando-se os ácidos nucléicos dessas linhagens de feijão.

Quadro 1. Valores de Rm das isoenzimas esterase, peroxidase, fosfatase ácida, malato desidrogenase (MDH) e leucina aminopeptidase (LAP) das sementes de feijão do cultivar Goiano Precoce linhagens de folha lisa e folha rugosa

\begin{tabular}{|c|c|c|c|c|c|c|c|c|c|}
\hline \multicolumn{2}{|c|}{ Esterase } & \multicolumn{2}{|c|}{ Peroxidase } & \multicolumn{2}{|c|}{ Fosfatase ácida } & \multicolumn{2}{|c|}{$\mathrm{MDH}$} & \multicolumn{2}{|c|}{ LAP } \\
\hline F. lisa & F. rugosa & F. lisa & F. rugosa & F. lisa & F. rugosa & F. lisa & F. rugosa & F. lisa & F. rugosa \\
\hline 0,11 & 0,11 & 0,37 & 0,37 & 0,11 & 0,12 & 0,29 & 0,30 & 0,20 & 0,23 \\
\hline 0,19 & 0,19 & & & 0,19 & 0,19 & 0,34 & 0,35 & 0,52 & 0,55 \\
\hline 0,38 & 0,38 & & & 0,24 & 0,25 & 0,39 & 0,41 & 0,76 & 0,76 \\
\hline & & & & 0,29 & 0,29 & 0,47 & 0,49 & & \\
\hline & & & & 0,36 & 0,35 & & & & \\
\hline & & & & 0,39 & 0,39 & & & & \\
\hline & & & & 0,50 & 0,49 & & & & \\
\hline & & & & 0,61 & 0,61 & & & & \\
\hline & & & & 0,70 & 0,71 & & & & \\
\hline
\end{tabular}


A partir dos dados apresentados pode-se considerar a eletroforese de isoenzimas uma técnica adequada para estudos genéticos, uma vez que possibilitou avaliar diferenças genéticas entre plantas dos cultivares de soja IAC 6 e IAC 9, através de seus perfis isoenzimáticos. Por outro lado, os dados eletroforéticos das duas linhagens de feijão são compatíveis com a sua similaridade genética, podendo ser usados no mapeamento de genes para a morfologia da folha.

\section{Agradecimentos}

Ao Dr. Eduardo Antonio Bulisani e ao Dr. Manoel Albino Coelho de Miranda, do Centro de Plantas Graníferas do Instituto Agronômico, Campinas, pelas sementes cedidas para análise e pelos esclarecimentos dados para a execução deste trabalho.

\section{Referências Bibliográficas}

ALFENAS, A.C.; PETERS, I.; BRUNE, W.; PASSADOR, G.C. Eletroforese de Proteínas e Isoenzimas de Fungos e Essências Florestais.1.ed., Viçosa: Universidade Federal de Viçosa, 1991. 242p.

CURY, J.A. Contribuição ao estudo de isoenzimas de sementes de feijão (Phaseolus vulgaris L.). São Paulo, 1980.97p. Tese (Doutorado) - Instituto de Química/Universidade de São Paulo.
DAVIS, B.J. Disk electrophoresis: Method and aplication to human serum proteins. Annals of New York Academic Science, New York, v.121, p.404-427, 1964.

KIIHL, R A.S.; MIRANDA, M.A.C.; GUIMARÃES, G.; MASCARENHAS, H.A.A.; BRAGA, N.R. Cultivar de soja IAC 6. Campinas, Instituto Agronômico, 1979. 5p. (Circular, 103)

LEE, T.G. Proteínas de reserva do feijão (Phaseolus vulgaris). São Paulo, 1978. 92p. Tese (Doutoramento em Bioquímica) - Departamento de Química, Universidade de São Paulo.

PALMER, G.; KILEN, T.C. Qualitative genetics and cytogenetic. In: Soybeans: Improvement, Production and Uses. J.R. WILCOX (Ed.). 2ed. Madison, American Society of Agronomy, 1987. p.135-209. (Agronomy, 16)

TANKSLEY, S.D.; ORTON, TJ. Developments in Plant Genetics and Breeding I. Isoenzymes in Plant Genetics and Breeding. Part B. Amsterdam, Elsevier Science Publishers, 1983. 197p.

VELLO, N.A.; HIROMOTO, D.M.; AZEVEDO FILHO, A.J.B.V. Coeficient of parentage and breeding of brazilian soybean germoplasm. Revista Brasileira de Genética, Ribeirão Preto, v.3, n.11, p.679-697, 1988.

WEEDEN, N.G.; GOTTLIEB, LD. The genetics of chloroplast enzymes. Journal of Heredity, Washington, v.71, p.392-396, 1981. 